\title{
Indian Ocean Dipole modulated wave climate of eastern Arabian Sea
}

\author{
T. R. Anoop ${ }^{1}$, V. Sanil Kumar ${ }^{1}$, P. R. Shanas ${ }^{1,2}$, J. Glejin ${ }^{1}$, and M. M. Amrutha ${ }^{1}$ \\ ${ }^{1}$ Ocean Engineering Division, CSIR-National Institute of Oceanography (Council of Scientific \& Industrial Research), \\ Dona Paula, Goa 403 004, India \\ ${ }^{2}$ Marine physics department, King Abdulaziz University, Jeddah, Saudi Arabia \\ Correspondence to: V. Sanil Kumar (sanil@nio.org)
}

Received: 8 September 2015 - Published in Ocean Sci. Discuss.: 27 October 2015

Revised: 6 February 2016 - Accepted: 16 February 2016 - Published: 7 March 2016

\begin{abstract}
Intrinsic modes of variability have a significant role in driving the climatic oscillations in the oceanic processes. In this paper, we investigate the influence of an interannual mode of variability, the Indian Ocean Dipole (IOD), on the wave climate of the eastern Arabian Sea (AS). Using measured, modeled and reanalysis wave data and reanalysis wind data, we show that the IOD plays a major role in the variability of wave climate of the study region. Due to the IOD-induced changes in equatorial sea surface temperature and sea level pressure, the winds from the northern AS gets modified and cause inter-annual variability in the wave climate over the eastern AS. The changes in wind field over the AS due to the IOD influence the generation or dissipation of the wave field and hence cause a decrease in northwest short-period waves during positive IOD and an increase during negative IOD.
\end{abstract}

\section{Introduction}

The northern Indian Ocean (IO) is a unique ocean as compared to northern Atlantic and Pacific oceans. Because of the land-locked northern boundary, the wind pattern in this region shows semiannual reversal and causes boreal summer (June-September) and winter (December-February) monsoons. Strong westerly wind in the equatorial IO is limited to short transition periods between the monsoons - both southwest (SW) and northeast (NE). The equatorial zonal wind reaches a maximum in April-May and in October-November (Hastenrath and Polzin, 2004). The wind in the eastern Ara- bian Sea (AS) shows a decreasing trend during October and November (Zieger et al., 2014, supplementary information).

Wind waves are a prominent feature of the ocean surface and play a major role in planning activities in the open ocean and in coastal zones (Anoop et al., 2015). Hence, comprehensive understanding of the properties of the waves and their potential changes are the major knowledge required for sustainable management of both the coastal and offshore region. The wave climate of the eastern AS shows a large response to seasons and has a maximum wave height during the SW monsoon season (Chempalayil et al., 2012; Glejin et al., 2013a; Sanil Kumar et al., 2014; Anoop et al., 2015). Glejin et al. (2012) analyzed the wave parameters in three locations of the eastern AS during the SW season and found that the wave height increased from south to north. Shanas and Sanil Kumar (2014) studied the changes in wind speed and significant wave height (SWH) in the eastern AS by analyzing 34 years data. The average SWH in the eastern AS during pre-monsoon (FMAM), SW monsoon (JJAS) and post-monsoon (ONDJ) are about $1,2.7$ and $0.7 \mathrm{~m}$ respectively with an annual average value of $\sim 1.1 \mathrm{~m}$ (Glejin et al., 2013a). Apart from seasonal variation, Aboobacker et al. (2011) observed distinct wave characteristics during the winter season (NE monsoon and early pre-monsoon) with a periodicity ranging from 2 to 5 days associated with shamal events in the northern AS. Glejin et al. (2013b) also observed the presence of summer shamal swells off Ratnagiri, a location in the eastern AS. The diurnal variation due to sea/land breeze has a large influence on the wind-sea climate of the eastern AS during the non-monsoon period (Neetu et al., 2006; Glejin et al., 2013a; Amrutha et al., 2016). Long- 
period southern hemispheric swells are present in the eastern AS except during the SW monsoon season (Glejin et al., 2013a).

The monsoon wind patterns in the northern IO affect the spatial distribution of sea surface temperature (SST) in the tropical IO. The SST distribution differs from that observed in the Pacific and Atlantic which are warmer in the west (Vinayachandran et al., 2009). In the IO, warm water is on the eastern side and cold water is on the western side (Vinayachandran et al., 2009). This SST difference varies during the coupled oceanic and atmospheric phenomena in the equatorial IO known as the Indian Ocean dipole (IOD) (Saji et al., 1999). Positive IOD (PIOD) is associated with decreases (increases) of SST and increases (decreases) of sea level pressure (SLP) over the eastern (western) tropical IO. The negative phase of IOD is intensification of the normal condition (Vinayachandran et al., 2009). In the equatorial IO, the IOD appears as a dominant contributor of SST variability during the boreal fall season (October-December) (Saji and Yamagatta, 2003). About $12 \%$ of the SST variability in the IO is associated with dipole mode events (Vinayachandran et al., 2009). There is a phase lag in the SST evolution between the eastern and western tropical IO (Saji et al., 2003) and the regions of positive anomaly (during PIOD) vary with year (Vinayachandran et al., 2009). The Dipole Mode Index (DMI) is a quantitative representation of the strength of the IOD and is a measure of the anomalous zonal SST gradient across the equatorial IO. It is defined as the difference between SST anomaly in a western $\left(60-80^{\circ} \mathrm{E}, 10^{\circ} \mathrm{S}-\right.$ $\left.10^{\circ} \mathrm{N}\right)$ and an eastern $\left(90-110^{\circ} \mathrm{E}, 10-0^{\circ} \mathrm{S}\right)$ box. Seasonal phase locking is an important characteristic of the DMI time series. It is moderately correlated with the nino3 (ENSO) index, but it is strongly correlated with equatorial winds over the IO (Saji et al., 1999). Monthly DMI are available on the website of the Japanese Agency of Marine-Earth Science and Technology (www.jamstec.go.jp).

The tropical IO displays strong inter-annual climate variability associated with the El Niño-Southern Oscillation (ENSO) and the IOD (Murtugudde et al., 2000; Slingo and Annamalai, 2000). Baquero-Bernal et al. (2002) found that the IOD shows good correlation with the ENSO in the equatorial Pacific Ocean. However, the correlation between the strength of ENSO and IOD is not linear (Shinoda and Han, 2005). IODs co-occurring with ENSO are forced by a zonal wind shift in the descending branch of Walker circulation in the eastern IO and the process that initiates IODs in the absence of ENSO is not clear (Vinayachandran et al., 2009).

The impact of IOD on the wind pattern in the equatorial IO is examined in the following studies. SST and SLP variation produced by the IOD cause easterly zonal wind anomaly especially in its zonal component in equatorial IO (Reverdin, 1985; Murtugudde et al., 2000; Saji et al., 1999; Webster et al., 1999; Sreenivas et al., 2012). The IOD-forced wind anomalies are maximum in the central equatorial IO (Sreenivas et al., 2012) - significant anomalies appear around

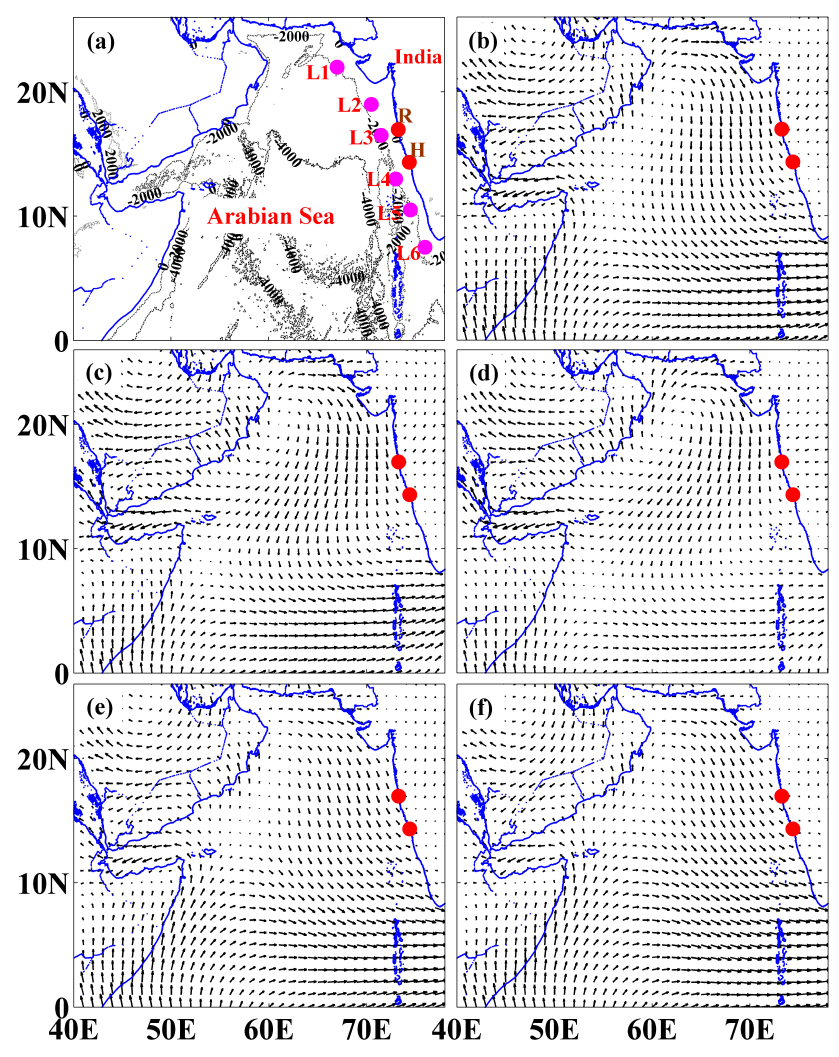

Figure 1. (a) The six locations considered to study the role of DMI on the wave climate are L1 to L6. The wave-measuring locations (Ratnagiri and Honnavar) in central eastern AS are shown as red dots. (b) Composite climatology of wind pattern during October in the AS and part of the equatorial Indian Ocean from 1958 to 2014. Averaged wind pattern during (c) pure positive IOD, (d) combined positive IOD, (e) pure negative IOD and (f) combined negative IOD from 1958 to 2014.

June, intensify in the following months and peak in October. The anomalous easterlies weaken the eastward Wyrtki jets (Wyrtki, 1971) in the equatorial IO (Reverdin, 1985). The wind anomaly produced during IOD has longer duration, but ENSO has shorter duration (Rao et al., 2002).

Although the influence of IOD on the wind pattern of the IO has been reported (Saji et al., 1999), the role of this event on the wave climate of the IO has not yet been studied. Glejin et al. (2013c) pointed out the possibility of influence of IOD on the wave climate of the southeast coast of India, but further analysis on this topic in this region has not been carried out. Most of the studies in the past have focused on the influence of IOD on the wind pattern of the equatorial IO. In this paper, we examine the impact of IOD on the surface wind field of the AS and its impact on the wave climate of the eastern AS. The analysis is confined to October, when the impact of the IOD is strongest and wind conditions in the AS are calmest. Figure 1a shows the study area. The data sets used in this study and the details of the numerical mod- 
els are described in Sect. 2. Section 3 describes results and discussion, and the main findings are summarized in Sect. 4.

\section{Data and methods}

The major challenge for wave climate study in the eastern AS is the scarcity of long-term observational data. In this study we use the available measured data of the Datawell directional waverider buoy off Ratnagiri (available from 2010 to 2014) and off Honnavar (available from 2008 to 2014) off the central west coast of India. Among these, Ratnagiri is the northern and Honnavar is the southern location and these locations are spaced $\sim 350 \mathrm{~km}$ apart. The details of the data analysis are similar to those presented in Sanil Kumar et al. (2014). The spectral climatology of the study area is presented by Sanil Kumar and Anjali Nair (2015).

Due to a lack of sufficient measured data, we used reanalysis products of the ECMWF (European Centre for MediumRange Weather Forecasts), (i) ERA-40 (Uppala et al., 2005) for the period 1958 to 1978 and (ii) ERA-I (Dee et al., 2011) for the period 1979 to 2014, to derive the wind climatology. The spatial resolution of ERA- 40 is $1.5^{\circ} \times 1.5^{\circ}$ and of ERA-I is $1^{\circ} \times 1^{\circ}$. The performance of ERA-I was previously evaluated over tropical and northern IO and showed good performance compared with observation for wind and wave (Kumar et al., 2013; Shanas and Sanil Kumar, 2014; Sanil Kumar and Naseef, 2015). In the present study, blended data sets of ERA-40 and ERA-I are used only for long-term wind field analysis during positive, negative and neutral IOD years. Since ERA-I is the improved version of ERA-40 (Dee et al., 2011), we compared ERA-40 with ERA-I during October from 1979 to 2001 (Fig. 2). From the analysis, it is clear that the error in ERA-40 compared to ERA-I will not significantly affect the results when we blend these data sets together. For SST data we used the daily averaged Tropflux SST with $1^{\circ} \times 1^{\circ}$ resolution from 1979 to 2014 (Kumar et al., 2012).

In order to simulate the directional wave spectrum at the buoy location, we have used two third-generation spectral wave models; WAVEWATCH III (WW3) 4.18 and Simulating Waves Nearshore (SWAN) 41.01. WW3 is the wave model developed by NOAA/NCEP (Tolman, 1991, 2009) and is based on finite difference solving of the energy balance equation of the spectral wave action in the approximation of phase averaging. The coastal wave model SWAN is a third-generation, phase-averaged numerical wave model for the simulation of waves in waters of deep, intermediate and finite depth (Booij et al., 1999). The physical parameterization of model physics of WW3 is described in several works (e.g., Tolman, 1991, 2009) and that for SWAN by Booij et al. (1999), Ris et al. (1999) and Bunney (2011). We have implemented a coarse-resolution WW3 model with a resolution of $0.25^{\circ} \times 0.25^{\circ}$ in latitude and longitude covering the entire domain in the IO $\left(20-78^{\circ} \mathrm{E}\right.$ and $\left.70^{\circ} \mathrm{S}-35^{\circ} \mathrm{N}\right)$ and a SWAN model with relatively finer grid of $1 \mathrm{~min}$ in the NIO (70-

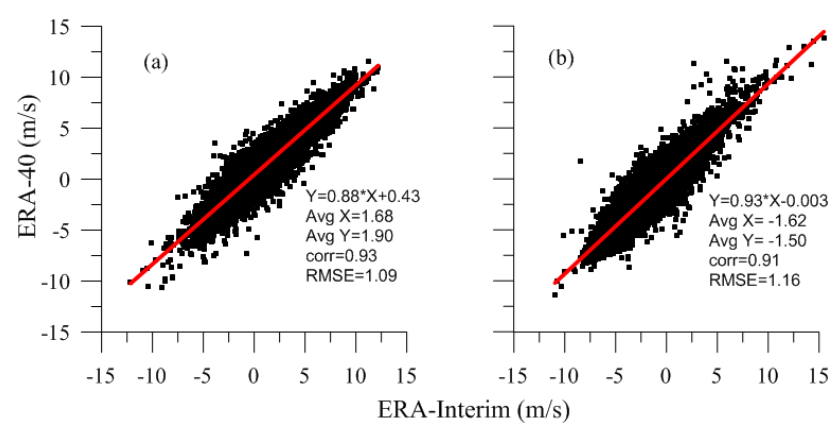

Figure 2. Cross-comparison of ERA-40 and ERA-I for October from 1979 to 2001. (a) zonal wind (b) meridional wind.

$75^{\circ} \mathrm{E}$ and $10-20^{\circ} \mathrm{N}$ ). We used high-resolution bathymetry from the $1 \mathrm{~min}$ gridded elevations/bathymetry for the world (ETOPO1) database (Amante and Eakins, 2009) available from the National Geophysical Data Center (NGDC, United States).

Wave frequencies were discretized over 25 bins on a logarithmic scale from 0.04 to $1 \mathrm{~Hz}$; wave direction was binned into 36 intervals of $10^{\circ}$ each. The WW3 run was carried out using physical processes contained in source term package-2 (ST2) (Tolman and Chalikov, 1996). The terms selected are bottom friction and depth-induced breaking (Hasselmann et al., 1973). The wind growth and white capping (Komen et al., 1984), quadruplet and triad interaction processes were activated. The WW3 model is driven by the surface wind fields from ERA-I at every $6 \mathrm{~h}$ interval and the time series 2-dimensional energy density spectra obtained is used as the boundary condition for the higher-resolution nearshore wave model SWAN. For comparison of the SWH estimated in deep water using WW3, the measured wave data collected using a moored Seatex buoy (Oceanor, Norway) under the National Data Buoy Program (Premkumar et al., 2000) at AS2 location in the $\operatorname{AS}\left(15.00^{\circ} \mathrm{N} ; 69.00^{\circ} \mathrm{E}\right.$; water depth $\left.\sim 3000 \mathrm{~m}\right)$ during October 2009 are used. The heave data of the buoy are recorded at $2 \mathrm{~Hz}$ interval for $17 \mathrm{~min}$ duration and from the recorded heave data, the wave spectrum is obtained through fast Fourier transform, and the SWH is estimated from the zeroth spectral moment $\left(m_{0}\right)$ as SWH $=4 \sqrt{m_{0}}$. For quantitative comparison between measured and model output, several error statistics have been determined; Pearson's linear correlation coefficient $r$, root-mean-square error (RMSE), bias, and scatter index (SI). The comparison of model results with measured data in deep water was carried out only for October 2009 , since our study is only on the influence of IOD on the wave climate during October. But for the shallow water area (Ratnagiri) which is our area of interest, we carried out validation for 2011 from September to November (Fig. 3). From this it is found that for shallow and deep water both models show 0.95 correlation, whereas for deep water the model is slightly underestimating $(-0.13 \mathrm{~m})$ and for shallow water it is overestimating $(0.06 \mathrm{~m})$. The scatter index and RMSE of 

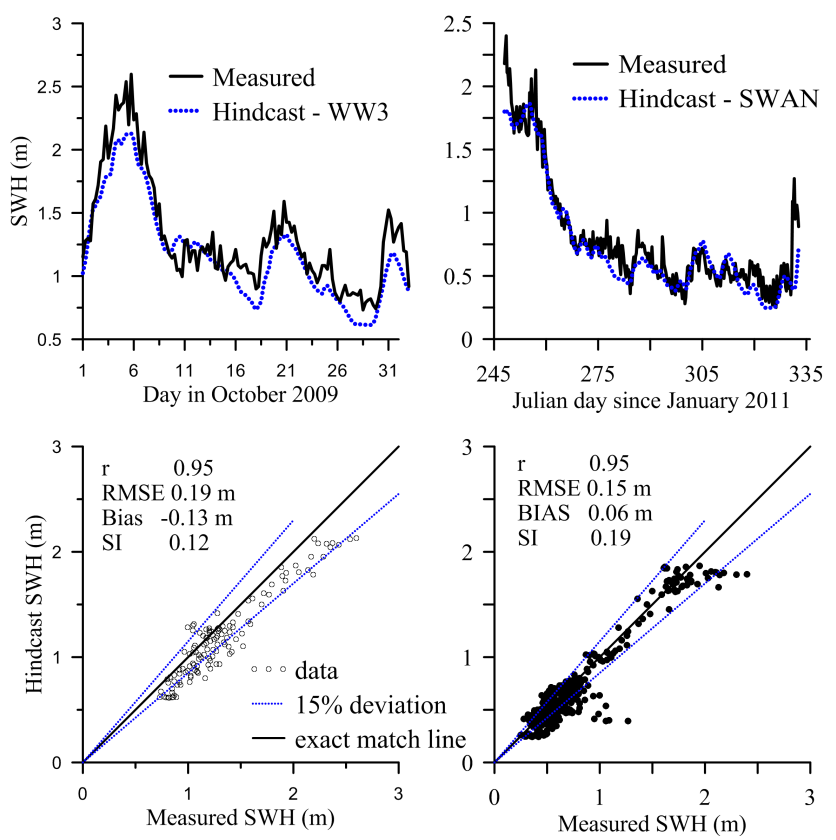

Figure 3. Comparison of hindcast SWH values with measured values. Left panel shows the values during October 2009 at deep-water location and the right panel shows the values during SeptemberNovember 2011 at shallow-water location (Ratnagiri).

both models are very small. From this we can see that the model shows good performance in both deep- and shallowwater areas.

\section{Results and discussion}

During October and November, the waves in the AS are dominated by low-amplitude (SWH $<1 \mathrm{~m}$ ) wind seas (Young, 1994; Chempalayil et al., 2012; Glejin et al., 2013a), and during this time the DMI reaches its maximum value. For this particular period we examined the role of DMI on the wave climate of the eastern AS and observed that during October surface waves in this region show a response to DMI. We selected six locations (Fig. 1a) along the eastern AS which are at more than $100 \mathrm{~km}$ away from the coast of India (Table 1). The time series plot of SWH and mean wave period (MWP) with DMI are shown in Fig. 4a. Correlation and partial correlation of the wave parameters with DMI and SOI (southern oscillation index) are shown in Table 1 and this shows that SWH is negatively related and MWP is positively related to DMI. The influence of IOD increases towards the south, but after removing ENSO (SOI) the correlation values in all locations decrease and maximum correlation is observed in the central AS (location L4). This implies that if influences of ENSO are removed, then IODs have more impact on the central eastern AS than further north or south. The impact of ENSO with and without IOD was checked here and it is identified that without the IOD, the impact of ENSO is significant

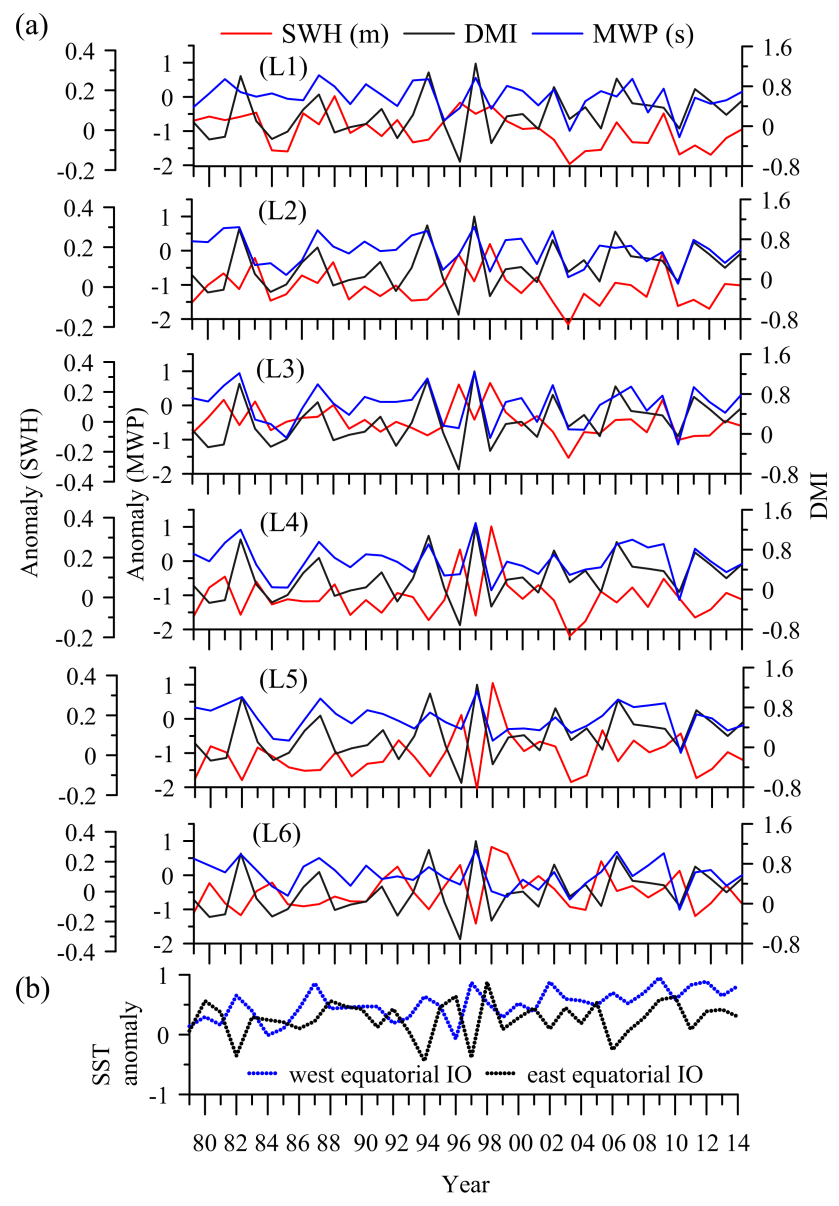

Figure 4. (a) Anomaly of significant wave height (SWH) and mean wave period (MWP) at six selected locations off the west coast of India during October from 1979 to 2014 along with DMI. The wave data are from ERA-I. Locations are shown in Fig. 1. (b) Plot of SST anomaly in the west and east equatorial IO. SST data are from Tropflux.

only in the southern part of the eastern AS. From this it is certain that in the eastern AS region IOD has more impact than ENSO and its effect is dominant off the central west coast of India. The variability of SWH and MWP with respect to the DMI index from 1979 to 2013 is shown in time series plot at the same six locations (Fig. 4a). The anomaly in the SWH varies between -0.2 and $0.4 \mathrm{~m}$ and that for MWP from -2 to $1 \mathrm{~s}$. Maximum SWH and MWP anomaly is observed during 1997, which is the strongest IOD year of the study period.

The composite climatology (using ERA-40 and ERA-I) of October wind pattern (from 1958 to 2014) of AS and a part of the equatorial IO is shown in Fig. 1b. The wave measuring locations (Ratnagiri and Honnavar) in central eastern AS are shown as red dots (Fig. 1a). The eastern AS region shows comparatively strong wind compared to the western AS. The wind from the northern AS passes parallel to the Indian west coast to the eastern equatorial IO after merging with equatorial westerly wind, while over the central AS the wind vectors 
Table 1. Correlation and partial correlation of SWH and MWP with DMI and NINO3 time series during October, from 1979 to 2014.

\begin{tabular}{|c|c|c|c|c|c|c|c|c|}
\hline & \multicolumn{2}{|c|}{$\begin{array}{c}\text { Correlation } \\
\text { with DMI }\end{array}$} & \multicolumn{2}{|c|}{$\begin{array}{l}\text { Partial correlation } \\
\text { with DMI } \\
\text { (ENSO removed) }\end{array}$} & \multicolumn{2}{|c|}{$\begin{array}{l}\text { Correlation } \\
\text { with ENSO }\end{array}$} & \multicolumn{2}{|c|}{$\begin{array}{c}\text { Partial correlation } \\
\text { with ENSO } \\
\text { (DMI removed) }\end{array}$} \\
\hline & SWH & MWP & SWH & MWP & SWH & MWP & SWH & MWP \\
\hline $\mathrm{L} 1\left(22^{\circ} \mathrm{N} ; 67^{\circ} \mathrm{E}\right)$ & -0.16 & 0.37 & -0.19 & 0.23 & -0.02 & 0.30 & 0.11 & 0.10 \\
\hline $\mathrm{L} 2\left(19^{\circ} \mathrm{N} ; 70.5^{\circ} \mathrm{E}\right)$ & -0.27 & 0.48 & -0.20 & 0.29 & -0.19 & 0.45 & 0.03 & 0.20 \\
\hline $\mathrm{L} 3\left(16.5^{\circ} \mathrm{N} ; 71.5^{\circ} \mathrm{E}\right)$ & -0.38 & 0.68 & -0.31 & 0.51 & -0.22 & 0.53 & 0.03 & 0.17 \\
\hline $\mathrm{L} 4\left(13^{\circ} \mathrm{N} ; 73^{\circ} \mathrm{E}\right)$ & -0.56 & 0.69 & -0.40 & 0.52 & -0.46 & 0.59 & -0.15 & 0.25 \\
\hline $\mathrm{L} 5\left(10.5^{\circ} \mathrm{N} ; 74.5^{\circ} \mathrm{E}\right)$ & -0.59 & 0.57 & -0.34 & 0.33 & -0.59 & 0.60 & -0.33 & 0.35 \\
\hline $\mathrm{L} 6\left(7.5^{\circ} \mathrm{N} ; 76^{\circ} \mathrm{E}\right)$ & -0.59 & 0.55 & -0.35 & 0.27 & -0.56 & 0.61 & -0.29 & 0.40 \\
\hline
\end{tabular}

(a)
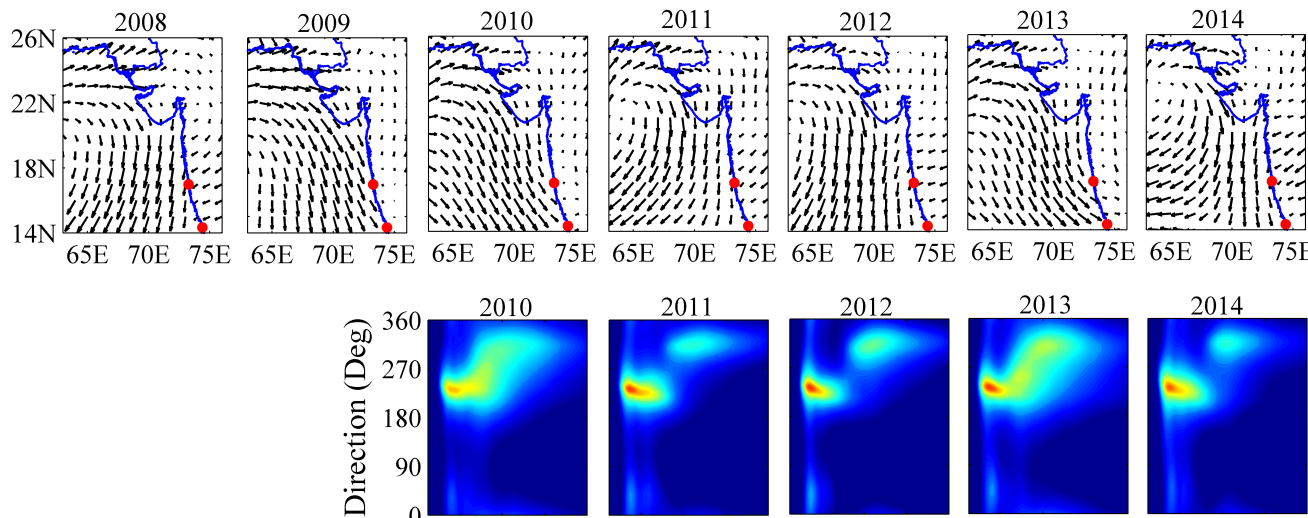

(b)
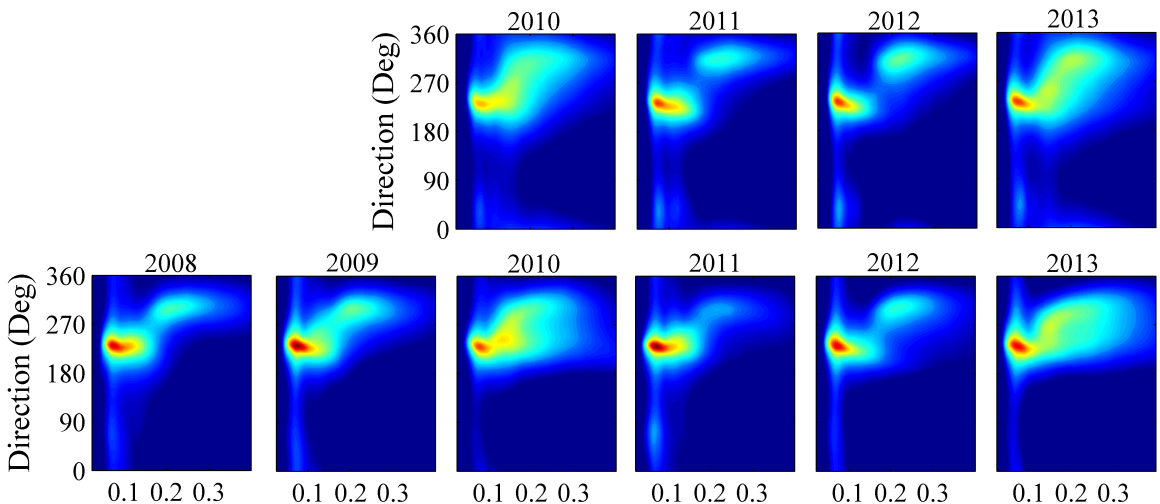

2014

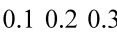

0.10 .20 .3

0.10 .20 .3

0.10 .20 .3

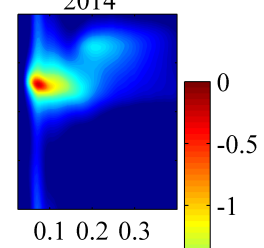

Frequency $(\mathrm{Hz})$
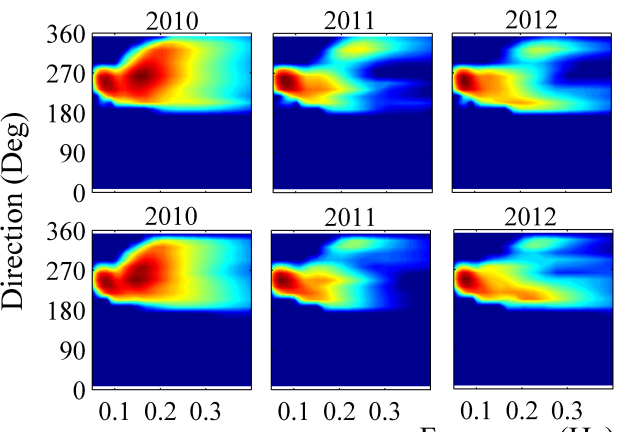

$\begin{array}{llll}0.1 & 0.2 & 0.3\end{array}$

$\begin{array}{llll}0.1 & 0.2 & 0.3\end{array}$

Frequency $(\mathrm{Hz})$
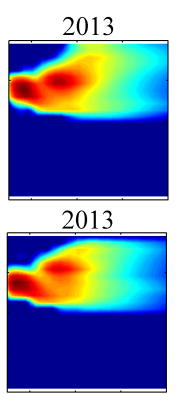

$0.10 .2 \quad 0.3$
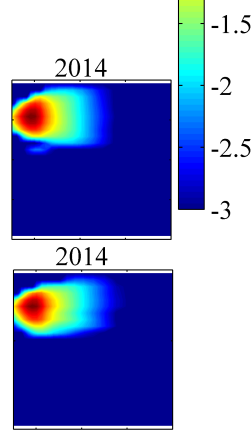

0.10 .20 .3

Figure 5. Averaged wind pattern of October from 2008 to 2014 (a). Averaged measured wave frequency-directional spectra from 2008 to 2014 off Ratnagiri (b) and off Honnavar (c). Color bar is for spectral energy $\left(\mathrm{m}^{2} \mathrm{~Hz}^{-1} \mathrm{Deg}^{-1}\right)$. (d) Modeled directional spectrum off Ratnagiri and (e) off Honnavar from 2010 to 2014. The spectral energy is shown in logarithmic scale base 10. SST anomalies of eastern and western equatorial IO with DMI are shown in Fig. 4.

are from the northerly direction and change to northwesterly before merging with the westerly equatorial winds and northwesterly winds nearer the Indian coast. This pattern of wind is due to the low pressure in the eastern equatorial IO due to the warm water in this region compared to the western equatorial IO (Vinayachandran et al., 2009). 


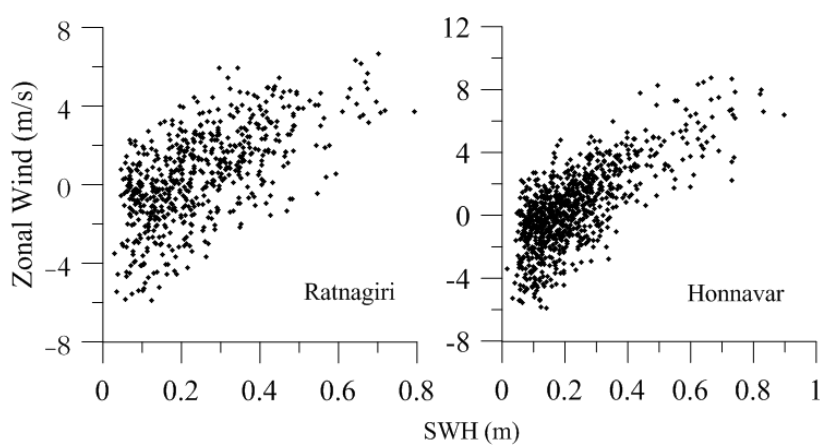

Figure 6. Scatter plot of zonal wind within 14 to $20^{\circ} \mathrm{N}$ and 70 to $73^{\circ} \mathrm{E}$ with SWH of high-frequency range $(0.14$ to $0.29 \mathrm{~Hz})$ and NW direction waves (280 to $320^{\circ}$ ) off Honnavar (from 2008 to 2014) and off Ratnagiri (from 2010 to 2014).

Pure positive IOD and combined events are considered following Aparna et al. (2012). A pure IOD event is that which occurs in the absence of an ENSO event (Rao et al., 2002). A positive (negative) IOD event that co-occurs with an El Niño (La Niña) is a combined IOD event. A pure ENSO event is defined similarly. The combined events are strong only if both El Niño and positive IOD events are strong. Figure $1 \mathrm{c}$ and $\mathrm{d}$ show the wind pattern during pure positive and combined IOD events respectively. As observed from climatology, these figures illustrate that in the eastern AS the northwesterly wind vectors are modified to northeasterly. Instead of going towards the eastern equatorial IO the wind blows towards the western IO. This can be perceived as more strong in combined event of PIOD with a comparatively weak wind vectors along the southwest of India. During the negative IOD (NIOD) events (Fig. 1e and f) wind blows over the central and eastern AS as northwesterly which is in contrast to the wind pattern during PIOD. This modification in the wind pattern over the central AS to either westward or eastward direction from its general climatology pattern during the PIOD or NIOD events is due to the IOD-induced temperature variability in the equatorial IO.

Measured frequency-directional spectra of surface waves from two locations off the central west coast of India are shown in Fig. 5. The wind pattern of corresponding years is shown in Fig. 5a and year wise SST anomaly in west, east and DMI index for October is shown in Fig. 4a and b. For the years 2008 to 2014, it can be seen that maximum positive DMI index is observed during 2011 (Fig. 4a). During this year the wind in the eastern AS has shifted its direction to northeasterly. Its influence is clearly visible in the frequency-directional spectra of waves at Ratnagiri and Honnavar, due to the decrease in short-period waves from the northwest (NW) direction. This difference in higher energy at Ratnagiri than Honnavar is clearly evident from Fig. $5 \mathrm{~b}$ and c and is caused by the alteration of wind direction to the NE before reaching Honnavar. So the dissipation of NW waves and weak wind in the Honnavar region causes a decrease in

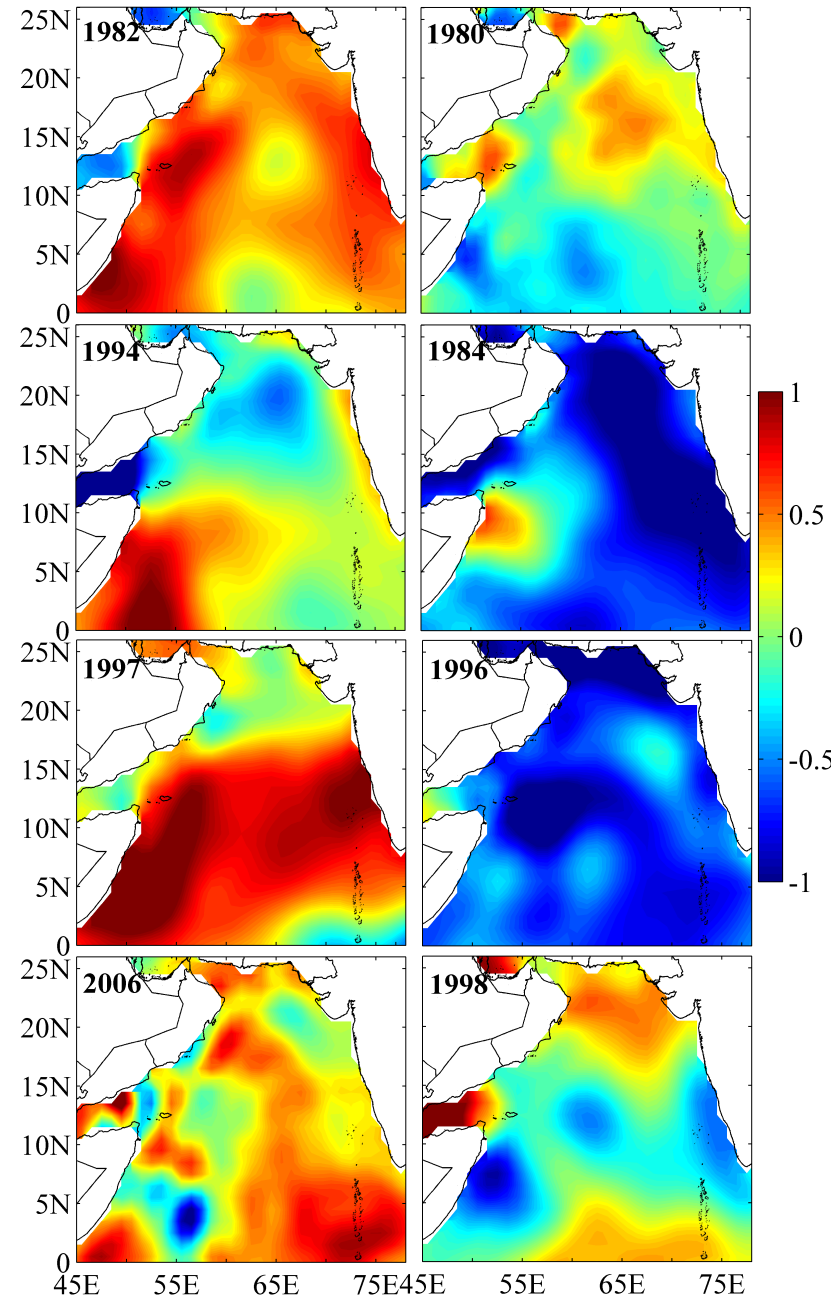

Figure 7. SST anomaly $\left({ }^{\circ} \mathrm{C}\right)$ of four strong positive (first column) and four negative (second column) IOD years from 1979 to 2014. Years are shown inside the figure and SST anomalies of eastern and western equatorial IO with DMI for corresponding years are shown in Fig. 4.

the short-period wave energy. Similar patterns are observed in other years such as 2008, 2012 and 2014 which has got comparatively higher DMI. Endo and Tozuka (2015) classified 2008 as IOD Modoki, and 2011 and 2012 as Canonical IOD years, and hence higher DMI is observed in these years.

In contrast to the above, the only year with negative DMI during 2008-2014 is in 2010. During 2010, the wind pattern is in the NW direction and the dominance of short waves from NW is higher. A similar pattern can be seen in 2009 and 2013 as these years also have low DMI index. Unlike PIOD, during negative IOD, the short-period waves are slightly higher at Ratnagiri than at Honnavar and this may be due to the dissipation of the waves from the NW due to the larger distance traveled by the waves to reach Honnavar than Ratnagiri. From Fig. 4b we can see that the maximum positive anomaly in SST of the western equatorial IO since 


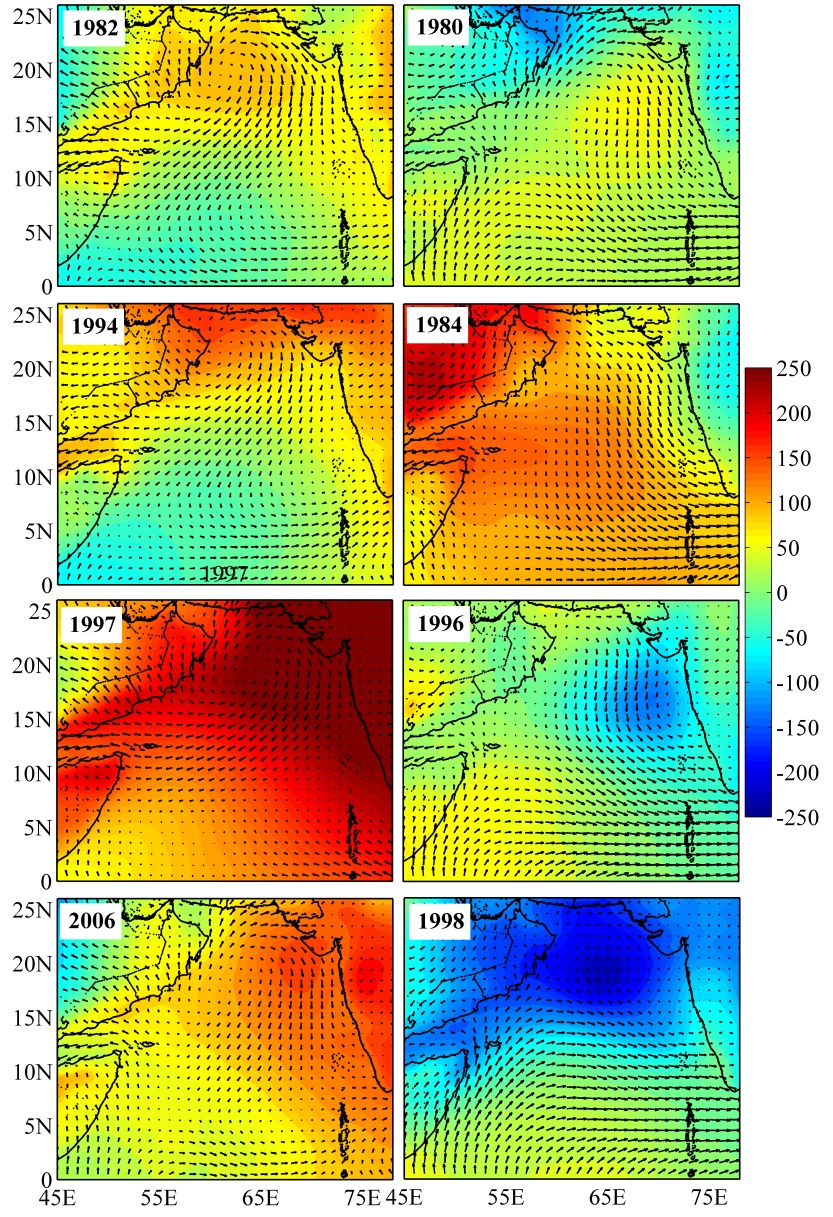

Figure 8. Wind vector $\left(\mathrm{m} \mathrm{s}^{-1}\right)$ and SLP anomaly (Pa) of four strong positive (first column) and four negative (second column) IOD years from 1979 to 2014. Years are shown inside the figure and SST anomalies of eastern and western equatorial IO with DMI for corresponding years are shown in Fig. 4.

2008 is observed in 2009. However, the influences of high SST anomalies are not observed either in the wind pattern or wave climate. This shows that the modification of wind vectors not only depends on the SST anomaly in the west or east separately but also on the DMI index.

To confirm the influence of IOD-induced turning wind pattern (Fig. 1b to $f$ ) on the waves off the west coast of India, we spatially averaged the zonal wind component within the region where wind shows alteration in its direction (14 to $20^{\circ} \mathrm{N} ; 70$ to $73^{\circ} \mathrm{E}$ ) and averaged the short period waves within the $0.14-0.29 \mathrm{~Hz}$ frequency range and $280-320^{\circ}$ direction. The scatter plot for both zonal wind and measured SWH in this particular direction and frequency range off Ratnagiri and off Honnavar for all years are shown in Fig. 6. From the figure it can be seen that the zonal wind component in this region has a direct influence to the wave climate of this region. SWH increases with the zonal wind component, and this increase is greater when the zonal wind component is positive than when it is negative.

During the negative phase of IOD, the swell height is slightly less than that during the positive phase (Fig. $5 \mathrm{~b}$ and c). The turbulent sea state generated by the dominance of short-period waves during the negative phase of IOD leads to an increased decay rate of swell (Ardhuin et al., 2009; Young et al., 2013). The sign reversal of the air-sea momentum flux depends on a parameter known as inverse wave age (ratio of sea surface wind speed to the speed of the wave corresponding to peak frequency) and it is very useful to understand the present sea state (Grachev and Fairall, 2001; Hanley and Belcher, 2008; Hanley et al., 2010). Here, we calculated the monthly (October) average inverse wave age off Ratnagiri and the values are 0.32, 0.11, 0.27, 0.35 and 0.17 from 2010 to 2014. From this it is further evident that during the positive phase of IOD, the eastern AS is a wave-driven wind region (inverse wave age $<0.15$ ) i.e., waves transfer momentum to wind. During the negative IOD period, the region becomes mixed state $(0.15<$ inverse wave age $<0.83$; both wind-driven wave and wave-driven wind are present). The modeled frequency-directional spectra off Ratnagiri and Honnavar from 2010 to 2014 are shown in Fig. 5d and e. Comparison of measured and modeled spectra off Honnavar and Ratnagiri shows that the spectral energy is overestimated by the model since the ERA-I wind data used in the study are with a coarse resolution of $1^{\circ} \times 1^{\circ}$ (Fig. 5b and c). Even though the model overestimated the spectral energy, it can be observed that the model reproduced almost the same pattern as the observed wave spectra. The influence of altering wind pattern is clearly evident in the modeled spectra as well.

Since IOD has large influence on SST variability in equatorial IO, here we show the SST of AS and western equatorial Indian Ocean in Fig. 7. We considered comparatively strong PIOD and NIOD events from 1979 to 2014. The PIOD years are 1982, 1994, 1997 and 2006 (left panel of Fig. 7). Among these in 1994, IOD occurs in the absence of ENSO. The NIOD years are 1980, 1984, 1996 and 1998 (right panel). This SST variability produces variability in SLP (Fig. 8). The wind pattern of the respective years for AS and part of equatorial IO are shown in the same figure. Since the NIOD is the intensification of the normal condition of October (Vinayachandran et al., 2009), the SLP in the western equatorial IO is higher and lower in the eastern equatorial IO. Hence, the winds from the northern AS will propagate towards the eastern equatorial IO along the eastern AS. This shows the influence of IOD-induced temperature variability on SLP and wind direction.

Since the performance of the numerical model is good we have carried out further analysis using this model for the period where measured data are not available. Simulated directional spectra for the years 1980, 1982, 1984, 1994, 1996, 1997, 1998 and 2006 are shown in Fig. 9. The first and third columns are for PIOD years off Ratnagiri and off Honnavar 

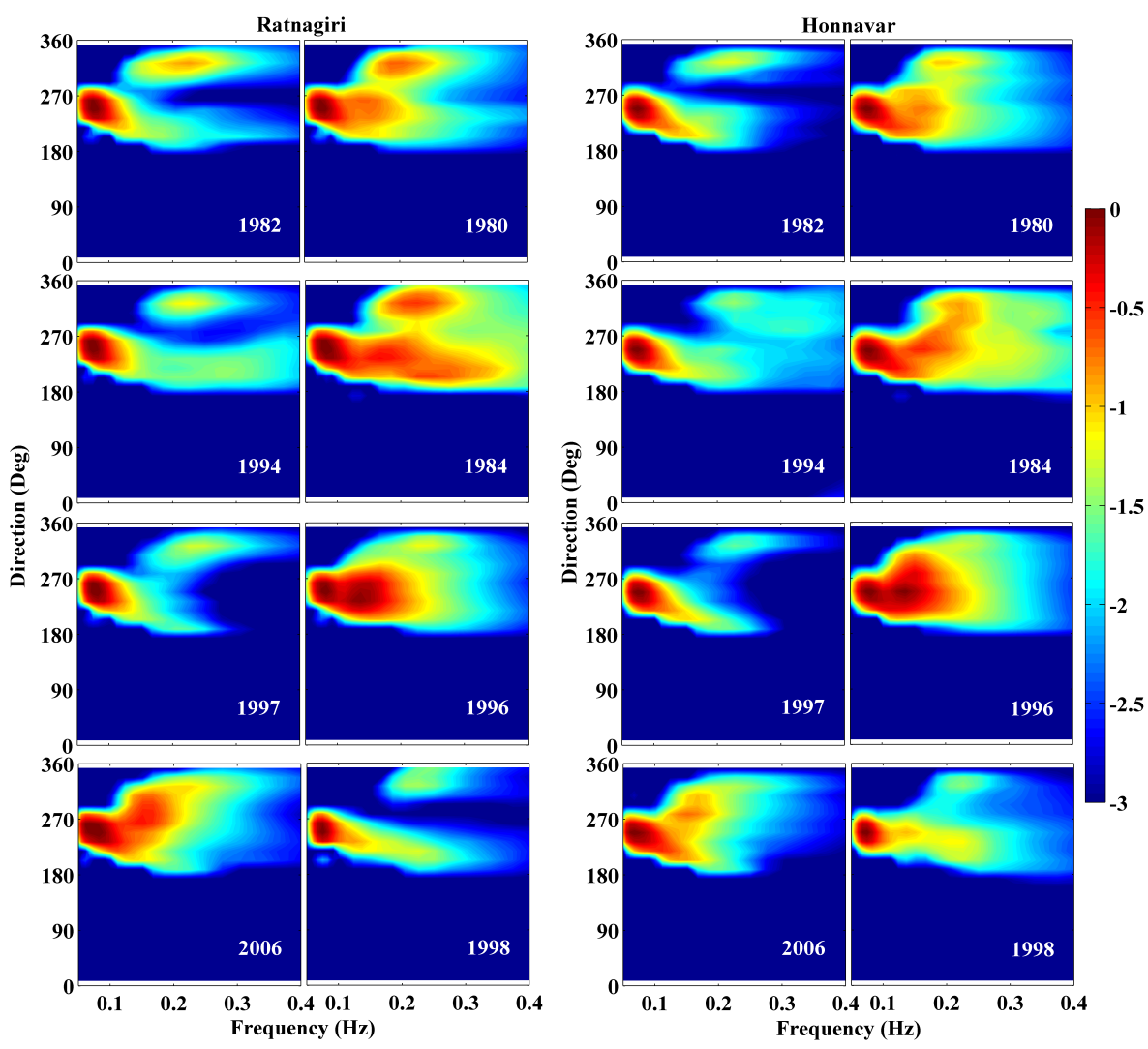

Figure 9. Modeled directional spectrum off Honnavar and Ratnagiri for selected positive and negative IOD years (first and third columns for positive IOD and second and fourth columns for negative IOD). Corresponding years are shown inside the figures and DMI are shown in Fig. 4. The spectral energy is shown in logarithmic scale base 10.

respectively; similarly the second and fourth columns are for NIOD years. From the figure it is evident that for the positive phase of IOD, the short-period waves from the NW direction are less at both locations, whereas 2006 shows a conflicting result. From Fig. 8, it is clear that in 2006 the wind pattern in the central AS is northeasterly as observed in the other PIOD events, but along the eastern AS the wind vector extends slightly further south compared to the strong events observed during 1994 and 1997. A similar pattern, but comparatively less spatial extension in wind vectors towards the south, is also evident during 1982 (Fig. 8).

In the case of 1996, which is the strongest NIOD event considered in this study, we expect a more evident signature in SWH at the study locations of Ratnagiri and Honnavar. However, in the wave spectrum its signature is weaker than that observed in 1980 and 1984 (Fig. 9). The wind pattern observed during the period, in 1996, is northerly down to $15^{\circ} \mathrm{N}$ then it turns northwesterly and propagates towards the eastern equatorial IO (Fig. 8). The change in wind pattern from the composite climatology of NIOD events (Fig. 1e and f) causes the weakening of short-period waves arriving from the NW and corresponding influence in the directional wave spectra. Similarly, the second strongest NIOD event occurred in 1998, but the signature of this event is absent in the wave climate. The northern-eastern AS region is calm due to the absence of NW winds in the northern AS, in turn due to the associated negative SLP anomaly.

\section{Conclusions}

We analyzed the wind pattern over the AS and examined the influence of IOD events on the October wave climate of the eastern Arabian Sea using reanalysis, observation, and model data sets. Analysis of wind pattern influenced by the IOD has been carried out by removing the influence of ENSO from IOD and vice versa. It has been found that IOD has significant influence on the wave climate off the central west coast of India compared to the northern and southern parts. The decreasing of wave height during PIOD is due to the decrease of short-period waves from the northwest direction. Wind blowing from the northern AS is the major determining factor on wave climate. In general, the climatology of wind pattern in central and eastern AS during October is northerly and northwesterly respectively. During PIOD events, the wind vector modifies its direction and blows as northeasterly because of the IOD-induced SST anomaly in the equatorial Indian Ocean. This brings a weakening of wind 
field over the central and south-of-central west coast of India. This change in direction of wind pattern in the AS causes a decrease in wave height off the central and southwest coast of India during PIOD, whereas during NIOD events the wind vector turns to northwesterly instead of northerly winds in the composite climatology over the region during October. This leads to an increase of short-period waves in the same region. The influence of IOD on the wave climate mainly depends on the modification of wind field caused by the phases of IOD event. If this wind pattern is absent even during a strong IOD event, then the signature of the IOD on the wave climate is also absent. This alteration of wind pattern mainly depends on the IOD-induced SST variability in the eastern and western equatorial IO, and some other unknown factors may also cause slight modification in this wind - more analysis is required to understand this variability. From this study it is clear that IOD has an impact on the wave climate off the west coast of India especially off the central west coast of India due to the decrease of northwesterly short-period waves.

Acknowledgements. The authors acknowledge the CSIR, New Delhi for funding the wave measurement at Honnavar and ESSO-INCOIS, Ministry of Earth Sciences, Government of India for funding the wave measurement at Ratnagiri. The director of CSIR-NIO, Goa provided encouragement to carry out the study. The deep water buoy data used for validation of the numerical model were collected by the National Institute of Ocean Technology, Chennai and provided by the Indian National Centre for Ocean Information Services (INCOIS) Ministry of Earth Sciences, Hyderabad. T. M. Balakrishnan Nair, A. Nherakkol and J. Singh provided support during data collection. We thank A. Vedpathak and P. Kulkarni, Centre for Coastal \& Marine Biodiversity, Dr. Babasaheb Ambedkar Marathwada University, Ratnagiri for providing the logistics required for wave data collection at Ratnagiri. This work forms part of the Ph.D. thesis of the first author. We thank the topic editor J. M. Huthnance and the two reviewers for their critical review and suggestions, which improved the scientific content of the paper. This work is NIO contribution no. 5866.

Edited by: J. M. Huthnance

\section{References}

Aboobacker, V. M., Rashmi, R., Vethamony, P., and Menon, H. B.: On the dominance of pre-existing swells over wind seas along the west coast of India, Cont. Shelf Res., 31, 1701-1712, 2011.

Amante, C. and Eakins, B. W.: ETOPO1 1 arc-minute global relief model: procedures, data sources and analysis, NOAA Tech. Memo., NESDIS NGDC-24, National Oceanic and Atmospheric Administration, Boulder, Colorado, USA, 19 pp., 2009.

Amrutha, M. M., Sanil Kumar, V., and Singh, J.: Changes in nearshore waves during the active sea/land breeze period off Vengurla, central west coast of India, Ann. Geophys., 34, 215-226, doi:10.5194/angeo-34-215-2016, 2016.

Anoop, T. R., Kumar, V. S., Shanas, P. R., and Johnson, G.: Surface wave climatology and its variability in the North Indian Ocean based on ERA-Interim reanalysis, J. Atmos. Ocean. Tech., 32, 1372-1385, doi:10.1175/JTECH-D-14-00212.1, 2015.

Aparna, S. G., McCreary, J. P., Shankar, D., and Vinayachandran, P. N.: Signatures of Indian Ocean Dipole and El Niño-Southern Oscillation events in sea level variations in the Bay of Bengal, J. Geophys. Res.-Oceans, 117, C10012, doi:10.1029/2012JC008055, 2012.

Ardhuin, F., Chapron, B., and Collard, F.: Observation of swell dissipation across oceans, Geophys. Res. Lett., 36, L06607, doi:10.1029/2008GL037030, 2009.

Baquero-Bernal, A., Latif, M., and Legutke S.: On dipole like variability of sea surface temperature in the tropical Indian Ocean, J. Climate, 15, 1358-1368, 2002.

Booij, N., Ris, R. C., and Holthuijsen L. H.: A third-generation wave model for coastal regions: 1 . Model description and validation, J. Geophys. Res.-Oceans, 104, 7649-7666, 1999.

Bunney, C.: A high resolution SWAN model assessment: North Norfolk to Humber, Forecasting Research Technical Report 557, Met Office, Devon, UK, 2011.

Chempalayil, S. P., Sanil Kumar, V., Johnson, G., Udhaba, D. G., and Vinayaraj, P.: Interannual and seasonal variations in nearshore wave characteristics off Honnavar, west coast of India, Curr. Sci. India, 103, 286-292, 2012.

Dee, D. P., Uppala, S. M., Simmons, A. J., Berrisford, P., Poli, P., Kobayashi, S., and Vitart F.: The ERA-Interim reanalysis: Configuration and performance of the data assimilation system, Q. J. Roy. Meteor. Soc., 137, 553-597, 2011.

Endo, S. and Tozuka, T.: Two flavors of Indian Ocean Dipole, Clim. Dynam., 1-15, doi:10.1007/s00382-015-2773-0, 2015.

Grachev, A. A. and Fairall, C. W.: Upward momentum transfer in the marine boundary layer, J. Phys. Oceanogr., 31, 1698-1711, 2001.

Hanley, K. E. and Belcher, S. E.: Wave-driven wind jets in the marine atmospheric boundary layer, J. Atmos. Sci., 65, 2646-2660, 2008.

Hanley, K. E., Belcher, S. E., and Sullivan, P. P.: A global climatology of wind-wave interaction, J. Phys. Oceanogr., 40, 1263 1282, 2010.

Glejin, J., Sanil Kumar, V., Sajiv, P. C., Singh, J., Pednekar, P., Kumar, K. A., Dora, G. U., and Gowthaman, R.: Variations in swells along eastern Arabian Sea during the summer monsoon, Open Journal of Marine Science, 2, 43-50, 2012.

Glejin, J., Sanil Kumar, V., Balakrishnan Nair, T. M., and Singh, J.: Influence of winds on temporally varying short and long period gravity waves in the near shore regions of the eastern Arabian Sea, Ocean Sci., 9, 343-353, doi:10.5194/os-9-343-2013, 2013 a.

Glejin, J., Sanil Kumar, V., Nair, T. M. B., Singh, J., and Mehra P.: Observational Evidence of Summer Shamal Swells along the West Coast of India, J. Atmos. Ocean. Tech., 30, 379-388, 2013b.

Glejin, J., Sanil Kumar, V., and Nair, T. M. B.: Monsoon and cyclone induced wave climate over the near shore waters off Puduchery, south western Bay of Bengal, Ocean Eng., 72, 277286, 2013c.

Hasselmann, K., Barnett, T. P., Bouws, E., Carlson, H., Cartwright, D. E., Enke, K., Ewing, J. A., Gienapp, H., Hasselmann, D. E., Kruseman, P., Meerburg, A., Müller, P., Olbers, D. J., Richter, K., Sell, W., and Walden, H.: Measurements of wind-wave growth and swell decay during the Joint North Sea Wave Project (JON- 
SWAP), Deutsche Hydrographische Zeitschrift, Supplement A., 8, 95 pp., 1973.

Hastenrath, S. and Polzin, D.: Dynamics of the surface wind field over the equatorial Indian Ocean, Q. J. Roy. Meteor. Soc., 130, 503-517, 2004.

Komen, G., Hasselmann, S., and Hasselmann, K.: On the existence of a fully developed wind-sea spectrum, J. Phys. Oceanogr., 14, 1271-1285, 1984.

Kumar, B. P., Vialard, J., Lengaigne, M., Murty, V. S. N., and McPhaden, M. J.: TropFlux: air-sea fluxes for the global tropical oceans-description and evaluation, Clim. Dynam., 38, 15211543, 2012.

Kumar, B. P., Vialard, J., Lengaigne, M., Murty, V. S. N., McPhaden, M. J., Cronin, M. F., Pinsard, F., and Reddy, K. G.: TropFlux wind stresses over the tropical oceans: evaluation and comparison with other products, Clim. Dynam., 40, 2049-2071, 2013.

Murtugudde, R., McCreary, J. P., and Busalacchi A. J.: Oceanic processes associated with anomalous events in the Indian Ocean with relevance to 1997-1998, J. Geophys. Res.-Oceans, 105, 3295-3306, 2000.

Neetu, S., Shetye, S. R., and Chandramohan, P.: Impact of sea breeze on wind-seas off Goa, west coast of India, J. Earth Syst. Sci., 115, 229-234, 2006.

Premkumar, K., Ravichandran, M., Kalsi, S. R., Sengupta, D., and Gadgil, S.: First results from a new observational system over the Indian Seas, Curr. Sci. India, 78, 323-330, 2000.

Rao, A. S., Behera, S. K., Masumoto, Y., and Yamagata, T.: Interannual subsurface variability in the tropical Indian Ocean with a special emphasis on the Indian Ocean Dipole, Deep Sea Res. Pt. II, 49, 1549-1572, 2002.

Reverdin, G.: Convergence in the equatorial surface jets of the Indian Ocean, J. Geophys. Res.-Oceans, 90, 11741-11750, 1985.

Ris, R. C., Holthuijsen, L. H., and Booij, N.: A third-generation wave model for coastal regions 2. Veri?cation, J. Geophys. Res.Oceans, 104, 7667-7681, 1999.

Saji, N. H. and Yamagata, T.: Structure of SST and Surface Wind Variability during Indian Ocean Dipole Mode Events: COADS Observations, J. Climate, 16, 2735-2751, 2003.

Saji, N. H., Goswami, B. N., Vinayachandran, P. N., and Yamagata, T.: A dipole mode in the tropical Indian Ocean, Nature, 401, 360363, 1999.

Sanil Kumar, V. and Anjali Nair, M.: Inter-annual variations in wave spectral characteristics at a location off the central west coast of India, Ann. Geophys., 33, 159-167, doi:10.5194/angeo-33-159$2015,2015$.

Sanil Kumar, V. and Naseef, T. M.: Performance of ERA-Interim wave data in the nearshore waters around India, J. Atmos. Ocean. Tech., 32, 1257-1269, 2015.
Sanil Kumar, V., Shanas, P. R., and Dubhashi, K. K.: Shallow water wave spectral characteristics along the eastern Arabian Sea, Nat. Hazards, 70, 377-394, 2014.

Shanas, P. R. and Sanil Kumar, V.: Temporal variations in the wind and wave climate at a location in the eastern Arabian Sea based on ERA-Interim reanalysis data, Nat. Hazards Earth Syst. Sci., 14, 1371-1381, doi:10.5194/nhess-14-1371-2014, 2014.

Shinoda T. and Han, W.: Influence of the Indian Ocean dipole on atmospheric sub seasonal variability, J. Climate, 18, 3891-3909, 2005.

Slingo, J. M. and Annamalai, H.: The El Nino of the century and the response of the Indian summer monsoon, Mon. Weather Rev., 128, 1778-1797, 2000.

Sreenivas, P., Gnanaseelan C., and Prasad, K. V. S. R.: Influence of El Niño and Indian Ocean Dipole on sea level variability in the Bay of Bengal, Global Planet. Change., 80, 215-225, 2012.

Tolman, H. L.: A third-generation model for wind waves on slowly varying, unsteady and inhomogeneous depths and currents, J. Phys. Oceanogr., 21, 782-797, 1991.

Tolman, H. L.: User manual and system documentation of WAVEWATCH III TM version 3.14. Tech. Note., 276, National Oceanic and Atmospheric Administration, National Weather Service, Maryland, USA, 194 pp., 2009.

Tolman, H. L. and Chalikov, D.: Source terms in a third-generation wind wave model. J. Phys. Oceanogr., 26, 2497-2518, 1996.

Uppala, S. M., Kållberg, P. W., Simmons, A. J., Andrae, U., Bechtold, V., Fiorino, M., and Woollen, J.: The ERA-40 reanalysis, Q. J. Roy. Meteor. Soc., 131, 2961-3012, 2005.

Vinayachandran, P. N., Francis, P. A., and Rao, S. A.: Indian Ocean dipole: processes and impacts, Current Trends in Science: Platinum Jubilee Special, Indian Academy of Sciences Bangalore, 569-589, 2009.

Webster, P. J., Moore, A. M., Loschnigg, J. P., and Leben, R. R.: The great Indian Ocean warming of 1997-1998: Evidence of coupled oceanic-atmospheric instabilities, Nature, 401, 356-360, 1999.

Wyrtki, K.: Oceanographic Atlas of the International Indian Ocean Expedition, Natl. Sci. Found., Washington, D.C., Usa. 531 pp., 1971.

Young, I. R.: Global ocean wave statistics obtained from satellite observations, Appl. Ocean. Res., 16, 235-248, 1994.

Young, I. R., Babanin, A. V., and Zieger, S.: The decay rate of ocean swell observed by altimeter, J. Phys. Oceanogr., 43, 2322-2333, 2013.

Zieger, S., Babanin, A. V., and Young, I. R.: Changes in ocean surface winds with a focus on trends of regional and monthly mean values, Deep Sea Res. Pt. 1, 86, 56-67, 2014. 